Article

\title{
Genetic Transformation of Tribonema minus, a Eukaryotic Filamentous Oleaginous Yellow-Green Alga
}

\author{
Yan Zhang ${ }^{1,2}$, Hui Wang ${ }^{1, *}$, Ruigang Yang ${ }^{3}$, Lihao Wang ${ }^{1}$, Guanpin Yang ${ }^{4}$ and Tianzhong Liu ${ }^{1, *}$ \\ 1 Key Laboratory of Biofuels, Key Laboratory of Shandong Energy Biological Genetic Resources, \\ Qingdao Institute of Bioenergy and Bioprocess Technology, Chinese Academy of Sciences, Qingdao 266101, \\ China; zhang_yan@qibebt.ac.cn (Y.Z.); wanglh@qibebt.ac.cn (L.W.) \\ 2 University of Chinese Academy of Sciences, Beijing 100049, China \\ 3 College of Liberal arts and Sciences, National University of Defense Technology, Changsha 410073, China; \\ h709966877@126.com \\ 4 College of Marine Life Sciences, Ocean University of China, Qingdao 266061, China; \\ yguanpin@mail.ouc.edu.cn \\ * Correspondence: wanghui@qibebt.ac.cn (H.W.); liutz@qibebt.ac.cn (T.L.); Tel.: +86-0532-80662735 (H.W. \& T.L.)
}

Received: 13 February 2020; Accepted: 18 March 2020; Published: 19 March 2020

check for updates

\begin{abstract}
Eukaryotic filamentous yellow-green algae from the Tribonema genus are considered to be excellent candidates for biofuels and value-added products, owing to their ability to grow under autotrophic, mixotrophic, and heterotrophic conditions and synthesize large amounts of fatty acids, especially unsaturated fatty acids. To elucidate the molecular mechanism of fatty acids and/or establish the organism as a model strain, the development of genetic methods is important. Towards this goal, here, we constructed a genetic transformation method to introduce exogenous genes for the first time into the eukaryotic filamentous alga Tribonema minus via particle bombardment. In this study, we constructed pSimple-tub-eGFP and pEASY-tub-nptII plasmids in which the green fluorescence protein (eGFP) gene and the neomycin phosphotransferase II-encoding G418-resistant gene ( $n p t I I)$ were flanked by the T. minus-derived tubulin gene $(t u b)$ promoter and terminator, respectively. The two plasmids were introduced into T. minus cells through particle-gun bombardment under various test conditions. By combining agar and liquid selecting methods to exclude the pseudotransformants under long-term antibiotic treatment, plasmids pSimple-tub-eGFP and pEASY-tub- nptII were successfully transformed into the genome of T. minus, which was verified using green fluorescence detection and the polymerase chain reaction, respectively. These results suggest new possibilities for efficient genetic engineering of T. minus for future genetic improvement.
\end{abstract}

Keywords: Tribonema minus; particle-gun bombardment; tubulin gene; green fluorescence protein; transformation

\section{Introduction}

Eukaryotic microalgae are a very diverse group of organisms that have been reported to play vital roles in the fixation of $\mathrm{CO}_{2}, \mathrm{O}_{2}$ production, and climate change [1,2]. Furthermore, many groups of microalgae have great potential to produce a variety of commercially valuable carbon compounds, including lipids, starch, and carbohydrates, and specifically, they are well known for their ability to produce long-chain fatty acids, such as polyunsaturated fatty acids [3-5]. Therefore, these microalgae with rapid growth rates have been considered as possible sources of next-generation energy fuels and high-value products. 
The filamentous yellow-green algae Tribonema, which are widespread in freshwater and salt-water ecosystems, have gained substantial attention [6]. The T. minus strain has the ability to grow under autotrophic, mixotrophic, and heterotrophic conditions and synthesize large amounts of fatty acids, especially unsaturated fatty acids [7,8]. On one hand, T. minus is an industrial strain of microalgae that is used for biodiesel production under photoautotrophic conditions because of its high lipid content (up to $60.2 \%$ of its biomass) and easy harvesting characteristics due to its unbranched filaments. On the other hand, T. minus cells could be made economically feasible for the production of functional fatty acids with high value via heterotrophic/mixotrophic cultivation. In addition, a recent study by Wang et al. [9] revealed the molecular mechanisms of carbon partitioning during lipid accumulation in T. minus under photoautotrophic and heterotrophic conditions. Moreover, the recent genome sequencing of T. minus makes the species an attractive model for understanding the molecular nature of cell formation and lipid synthesis in the cells (the manuscript is undergoing preparation for publication). However, information on transgene expression and genetic engineering for understanding molecular mechanisms and strain development is very limited in the Tribonema genus.

The availability of facile and efficient transformation techniques for transgene expression and metabolic engineering is important for biotechnological application. Specifically, species-specific molecular operations in microalgae will allow for the engineering of improved performances to drive down manufacturing costs and overcome the economic threshold for the production of commercially competitive products. The identification and genetic manipulation in this organism are crucial steps for the improvement of lipid productivity and/or the growth rate in microalgae, and the establishment of a genetic transformation method is the first step towards this goal. To date, suitable transformation techniques have been established only in several limited unicellular models of eukaryotic microalgae, such as Chlamydomonas reinhardtii [10,11], Nannochloropsis sp. [12,13], Chlorella [14], and Phaedodactylum tricornutum [15]. Unfortunately, no research group has reported the stable genetic transformation of filamentous eukaryotic microalgae, including those from the Tribonema genus.

In Nannochloropsis sp. and other green algae, electroporation is a useful tool to introduce exogenous DNA into cells partially deprived of their cell walls $[16,17]$. Therefore, in our previous study, considering the filamentous characteristic of T. minus, we first attempted to use electroporation to introduce the plasmid into the protoplasts of this alga. However, although we tried to degrade the T. minus cell wall using several different enzymes that weaken the cell walls of other microalgal cells $[18,19]$, we have yet to prepare transformable protoplasts (data not shown). We then conducted particle bombardment experiments, as this method can successfully introduce exogenous DNA into cells with a rigid cell wall [20].

Here, in this study, the genetic transformation of T. minus, a natively robust and oleaginous algae, was investigated using a particle bombardment method. The efficient transformation conditions and some operational details in the transformation were determined by expressing the green fluorescent protein (eGFP) gene and neomycin phosphotransferase II-encoding G418-resistant (nptII) gene. These results suggest new possibilities for efficient genetic engineering of T. minus for future genetic improvements. This is the first report of a genetic engineering system in eukaryotic filamentous microalgae.

\section{Results}

\subsection{Growth Characterization of T. minus in Response to Herbicides and Antibiotics}

Transformability is usually tested using a plasmid harboring a selection marker (typically an antibiotic resistance gene) under the control of a promoter [21]. In order to select appropriate antibiotics for genetic manipulation, axenic cells of $T$. minus were first verified for herbicide and antibiotic sensitivity in liquid cultures. Five different antibiotics and one herbicide were assessed at various concentrations. The results showed that in liquid culture, T. minus is very sensitive to some of the antibiotics tested, particularly streptomycin and G418, causing $43.88 \%$ and $59.49 \%$ reductions in growth 
at concentrations of 10 and $20 \mu \mathrm{g} \mathrm{mL}^{-1}$, respectively, in 5 days (Figure 1A). T. minus was slightly less sensitive to hygromycin, which has been widely used as a selection marker for the transformation of eukaryotes [22,23], exhibiting growth reduction of about $50 \%$ at an antibiotic concentration of $50 \mu \mathrm{g} \mathrm{m}^{-1}$. Chloramphenicol and basta did not have strong effects on the growth of T. minus at low concentrations, but higher concentrations ( 100 and $150 \mu \mathrm{g} \mathrm{mL}^{-1}$ ) caused considerable inhibition to the biomass concentration of T. minus. On the other hand, kanamycin had almost no effect on the growth of T. minus (Figure 1A).
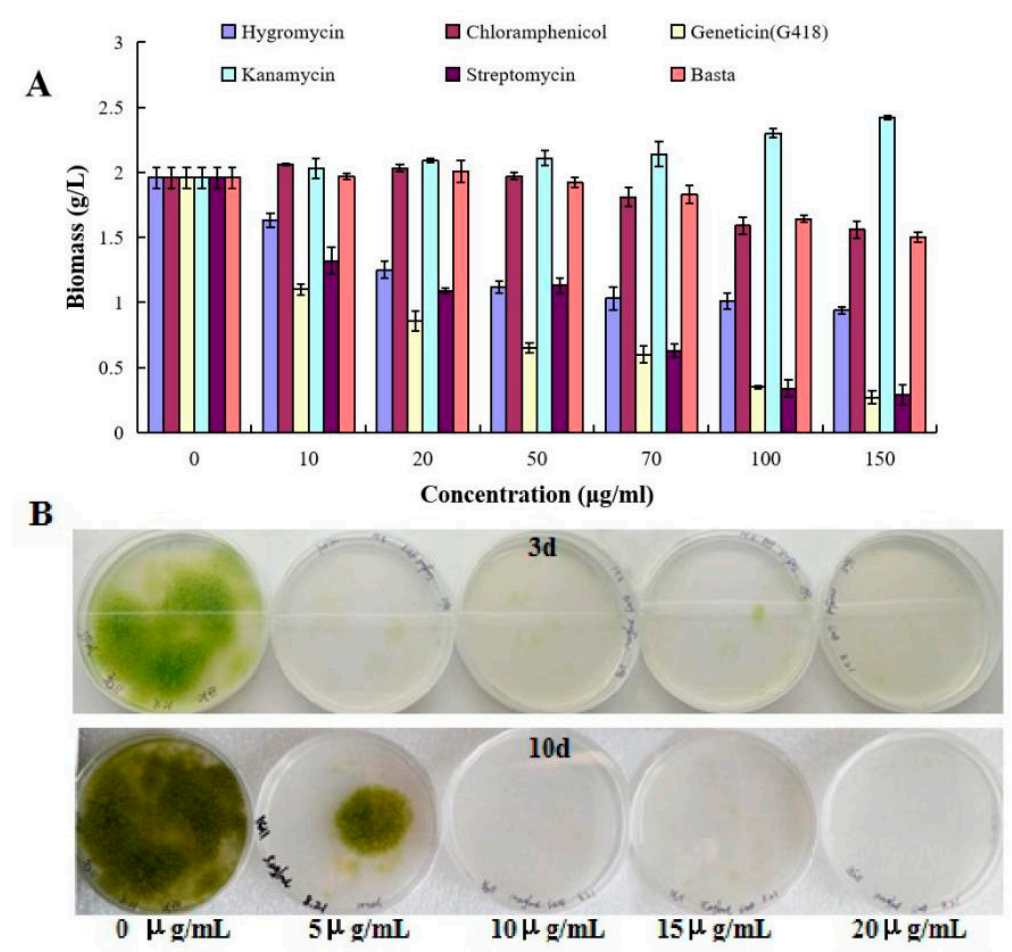

Figure 1. Analysis of herbicide and antibiotic sensitivities of T. minus. (A) Effects of different concentrations of all tested herbicides and antibiotics on the growth of T. minus in liquid medium. Five different antibiotics and one herbicide were used in this experiment, including hygromycin (light purple bars), chloramphenicol (dark red bars), geneticin (light yellow bars), kanamycin (light blue bars), streptomycin (dark purple bars), and basta (light red bars). Data are the average of $n=3$ independent repeats; bars show SDs. Significant differences in biomass changes under each antibiotic test $(p \leq 0.05)$.

(B) Growth of T. minus on the agar plates containing different concentrations of G418.

Our tests in liquid medium allowed us to analyze the effects of antibiotics in a quantitative, repetitive, and reliable way. However, in order to provide further information about the concentrations of antibiotics, especially G418, that are appropriate for the selection of transformants, we also assessed the effects of G418 on agar plates. Subsequently, the sensitivity of T. minus to G418 for genetic selection was examined on BG11-based agar plates with different concentrations $\left(5,10,15\right.$, and $\left.20 \mu \mathrm{gL}^{-1}\right)$ of G418. After 3 days, the cells cultured on agar plates without G418 had a good growth status, while those cultured with different concentrations of G418 did not show obvious growth. With prolongation of the cultivation, the results indicated that G418 at concentrations of $10 \mu \mathrm{g} \mathrm{mL} \mathrm{L}^{-1}$ and higher could effectively prevent the growth of T. minus, as the alga could still be grown on the plates at 10 days, giving a final concentration of $5 \mu \mathrm{g} \mathrm{mL} \mathrm{m}^{-1}$ (Figure 1B). Therefore, in accordance with the antibiotic sensitivity test, a G418-resistant gene encoding neomycin phosphotransferase II (nptII) was used as a selection marker gene [24] in this study. Additionally, the selective concentrations of 10 and $20 \mu \mathrm{g} \mathrm{mL}^{-1}$ were chosen for use in agar and liquid media, respectively. 


\subsection{Construction of Plasmids pSimple-tub-eGFP and pEASY-tub-nptII}

Besides the resistance selection marker, promoters and terminators are the other important elements for plasmid construction that direct transcription and termination, respectively. From the transcriptomic data, we found that the tub gene is expressed constitutively at a high level in T. minus, and thus, we used the upstream and downstream regions of the tub gene to provide promoter and terminator functions, respectively. We cloned and sequenced the tub gene (annotation number of MN481481 in Genbank) and its flanking sequences by the gene walking method, as described in the Methods section, and finally, we found that the nucleotide sequences comprised a promoter region (1373bp) and a terminator region (574bp) from the tub gene in T. minus (Figure 2A).

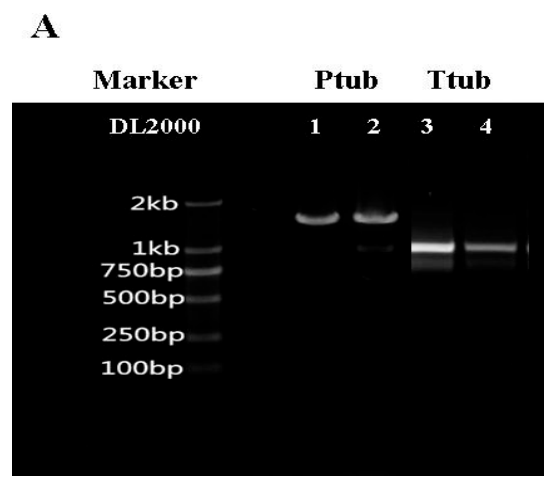

B

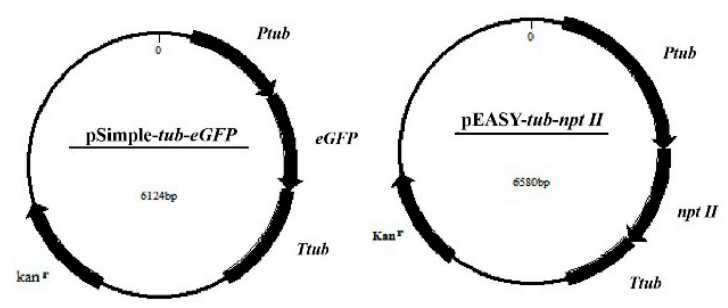

C

pSimple-tub-eGFP pEASY-tub-npt II

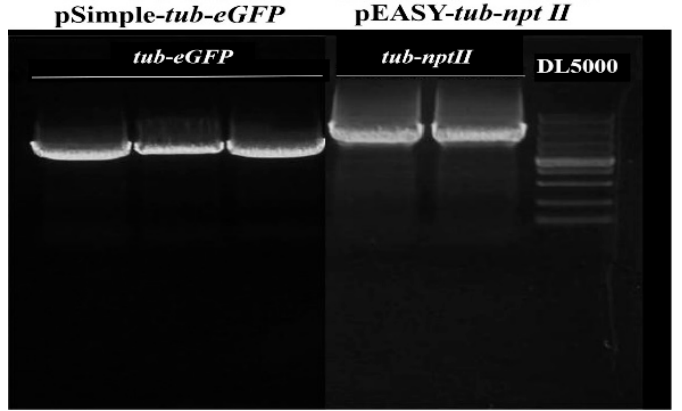

Figure 2. Construction of pSimple-tub-eGFP and pEASY-tub-nptII vectors. (A) Gel analysis of $t u b$ promoter and terminator. (B) Design structure and size of pSimple-tub-eGFP and pEASY-tub-nptII vectors. (C) Gel analysis of pSimple-tub-eGFP and pEASY-tub-nptII vectors.

A fusion PCR method was performed to fuse the genes of eGFP and nptII with the tub promoter and terminator of T. minus. After three fusions, we constructed two vectors that were controlled by the endogenous tub promoter and terminator with sizes of 6124 and $6580 \mathrm{bp}$, respectively, and we named the vectors pSimple-tub-eGFP and pEASY-tub-nptII (Figure 2C). The sequences of pSimple-tub-eGFP and Peasy-tub-nptII were also submitted to Genbank with the accession numbers MN496120 and MN481464, respectively. 


\section{3. pEASY-Tub-nptII Transformant Selection}

In a previous study, it was suggested that M17 tungsten particles work as DNA carriers because gold particles can easily adhere to the inner wall of Eppendorf tubes, which might lead to difficulties in the DNA coating process [25]. Additionally, the particles coated with at least $1 \mu \mathrm{g}$ DNA were utilized for one bombardment. Here, plasmid pSimple-tub-eGFP and pEASY-tub-nptII were transferred into T. minus cells by particle bombardment with various pressure conditions, as listed in the Methods section. In former tests, T. minus cells were easily shattered as the tungsten powder appeared on the filter membrane under higher pressure conditions. Hence, we layered another piece of filter membrane on the upper part of the cells prepared for transformation under a pressure of $900 \mathrm{psi}$ and higher.

For pEASY-tub-nptII transformants, after regeneration, cells were transferred onto an agar plate containing $10 \mu \mathrm{g} \mathrm{mL}^{-1}$ of G418. About 10 days later, we observed obvious vigorous congregated cells in agar that transformed under two pressure conditions of 450 and 900 psi (Figure 3A); however, no cells survived or were transferred under higher pressure levels, as the cells went grey. What needs to be emphasized is that $T$. minus cells on the agar plates exist in the form of an aggregate, not a single colony, because of their filaments.

\section{A}
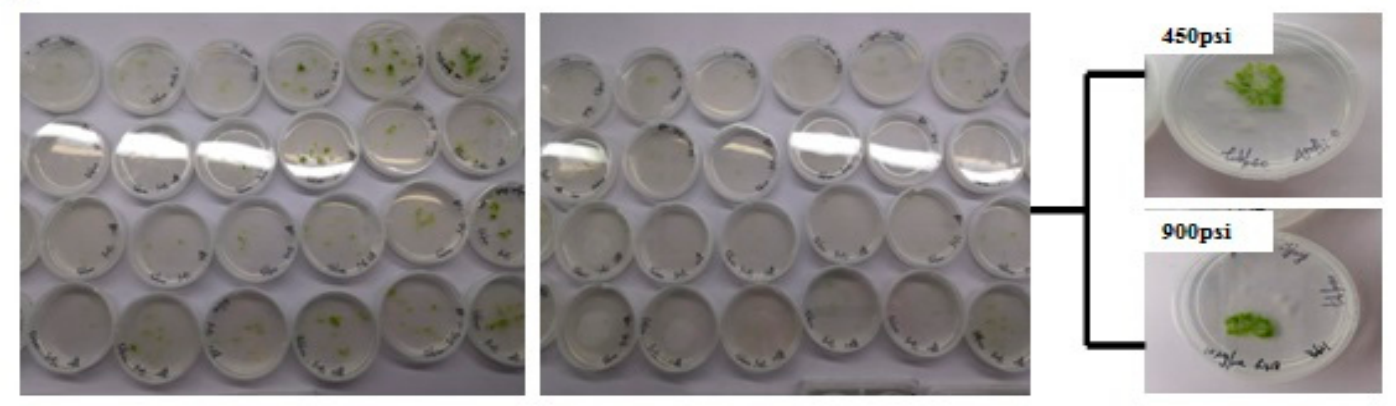

B

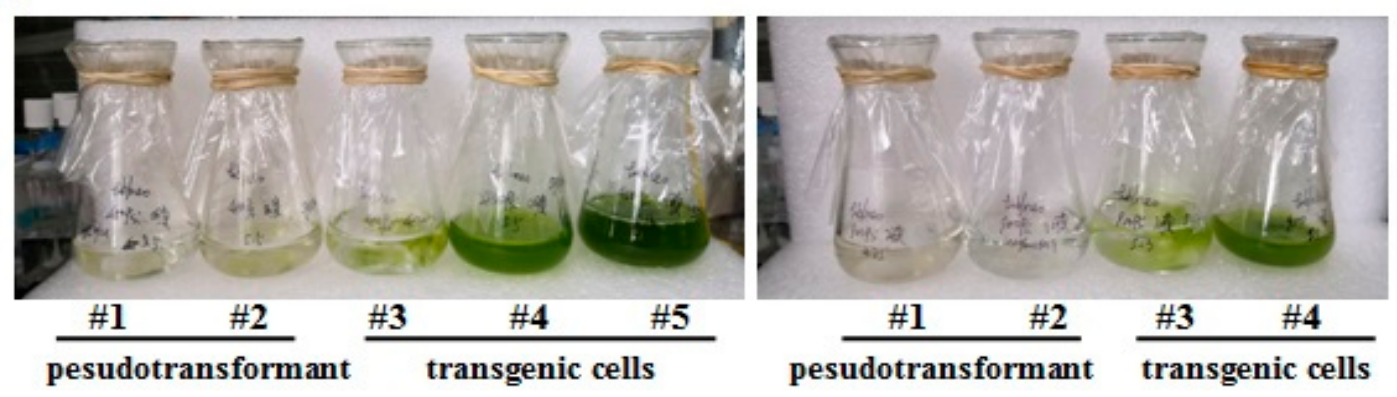

Figure 3. Agar and liquid selecting of transgenic cells. (A) Cells grown on an agar plate containing $10 \mu \mathrm{g} \mathrm{mL} \mathrm{m}^{-1}$ G418. (B) After growth, cells were transferred from the agar plate to BG11 medium supplemented with $20 \mu \mathrm{g} \mathrm{mL}^{-1} \mathrm{G} 418$.

Nevertheless, there might be such a phenomenon where there was no cell that transformed into exogenous DNA in the filament, but we could still observe the cells growing on the plates because there were some cells that did not directly contact antibiotics due to the filamentous characteristic. That resulted in some pseudotransformants. Therefore, we tried our best to pick as few cells as possible to be transferred into BG11 liquid medium supplemented with $20 \mu \mathrm{g} \mathrm{mL} \mathrm{m}^{-1} \mathrm{G} 418$ for further screening of transgenic cells, because the transformant cells could produce many new transgenic cells due to the genus growing by cell division [26], while the cells that did not transform successfully died under long-term antibiotic treatment. Figure 3B shows the growth status of cells transferred from G418-resistance agar plates. This revealed that regardless of the pressure, $450 \mathrm{psi}$ or $900 \mathrm{psi}$, not all cells that survived in the agar plates could grow under long-term antibiotic treatment in BG11 
liquid medium. It could be suggested and concluded that the transgenic cells grew on the selection, whereas the wild-type and pseudotransformant cells were not able to survive due to selection pressure.

\subsection{Confirmation of Transformation into the T. minus Genome}

After $48 \mathrm{~h}$ of regeneration, pSimple-tub-eGFP transformants were immediately observed with fluorescence analysis. Since the fluorescence from GFP was green and the autofluorescence from chloroplasts was red, transformant cells could be easily distinguished from wild-type cells. We observed the cells treated with particle bombardment under 450, 900, 1100, and 1350 psi; however, there was almost no obvious corresponding color found in samples of 900, 1100, and 1350 psi. Phenotypic characterization of T. minus transformed by pSimple-tub-eGFP under 450 psi is illustrated in Figure 4. The red autofluorescence from chloroplasts in wild-type cells is shown in Figure 4A,B, while green fluorescence was observed in transformed cells containing the $e G F P$ gene. Figure 4 gives intuitive evidence that the eGFP gene was successfully transformed into T. minus cells under $450 \mathrm{psi}$. Interestingly, the color of the entire filament changed, as shown in Figure $4 \mathrm{~A}, \mathrm{~A}^{\prime}$; however, as shown in Figure $4 \mathrm{~B}, \mathrm{~B}^{\prime}$, the corresponding color was just observed in single or several cells. This is a normal phenomenon because it is difficult for the eGFP genes to be transformed into each cell composing the entire filament.
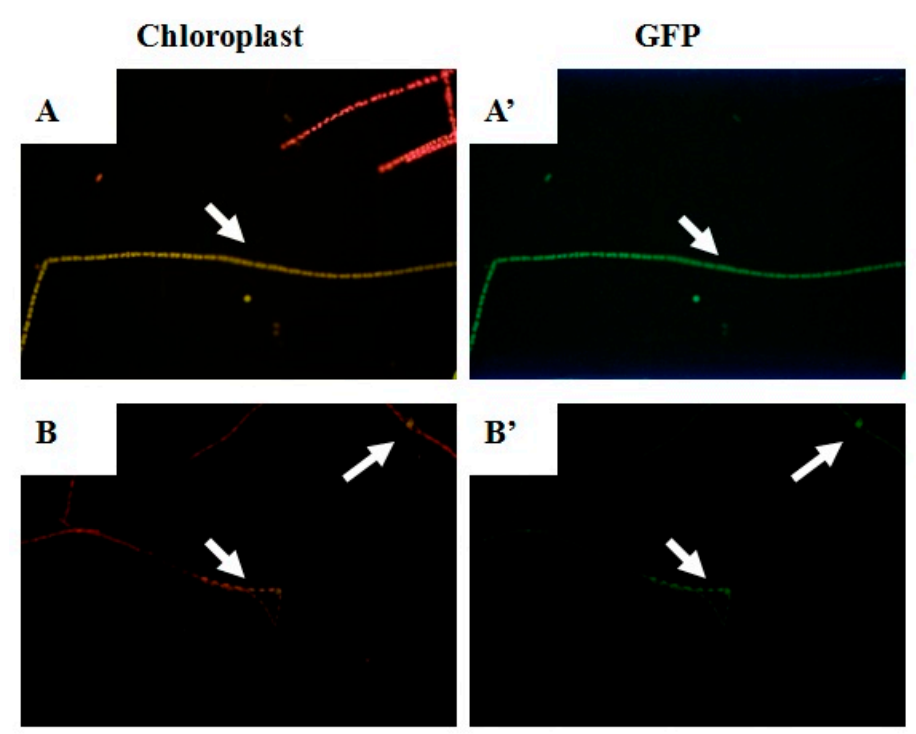

Figure 4. Phenotypic characterization of pSimple-tub-eGFP transformed T. minus under 450 psi. Detection was in the range of $685-735 \mathrm{~nm}$ for chloroplast autofluorescence (A, B) and 495-556 nm for eGFP $\left(\mathbf{A}^{\prime}, \mathbf{B}^{\prime}\right)$.

In order to check the presence of the plasmid DNA in transformants, both the predicted transgenic cells that grew well in BG11 medium supplemented with $20 \mu \mathrm{g} \mathrm{mL}^{-1} \mathrm{G} 418$ and the pSimple-tub-eGFP positive transformants were examined by genomic PCR analysis. Transgenic cells under 450 and 900 psi were picked, and the genomic DNA was extracted and used for PCR amplification of the nptII and eGFP gene fragments, respectively. As illustrated in Figure 5A,B, both the nptII (795bp) and eGFP genes (411bp) were detected in transformants. Moreover, $18 \mathrm{~S}$ rDNA was detectable in all samples except for the vector control, indicating the successful transformation of T. minus (data not shown). 


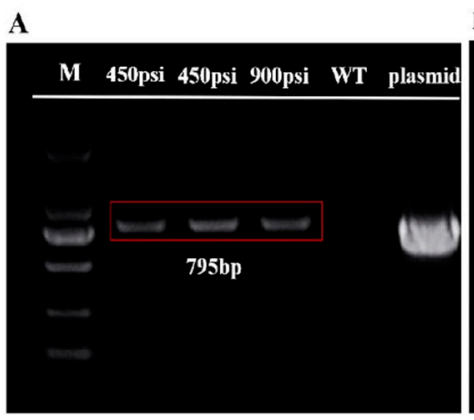

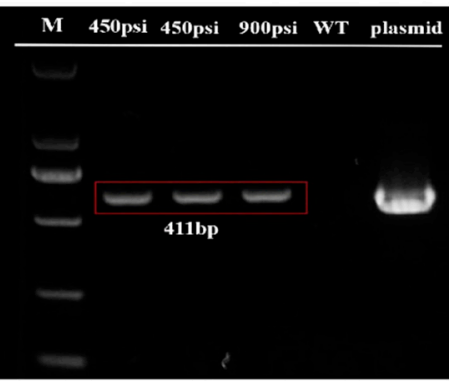

C

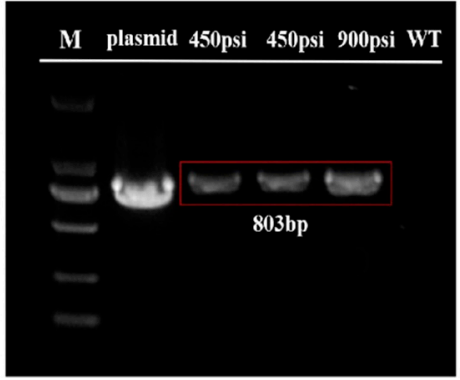

Figure 5. PCR amplification from genes using the genomic DNA of T. minus transformants and wild types (marker: DL2000). Gel analysis of the nptII (A) and eGFP genes (B) in transformants and wild types. (C) Gel analysis of fragment in pEASY-tub-nptII in third-generation transformants and wild types.

In addition, three pEASY-tub-nptII transgenic cells under 450 and 900 psi were picked randomly and transferred into fresh BG11 medium for a subculture until the third generation. Moreover, according to the sequence of pEASY-tub-nptII, we chose a middle fragment with a size of $803 \mathrm{bp}$ including part of the nptII gene and part of the tub promoter at random and designed the primers to have sequences of T-PK-F (5'-gcaatttgattggccagcgcaac-3') and T-PK-R (5'-gatggatactttctcggcaggag-3'). We amplified this fragment in the genomic DNA extracted in the third-generation transgenic cells, and the wild type was regarded as the control. Not surprisingly, Figure 5C reveals the presence of this fragment in all transgenic cells.

\subsection{Quantitative Analysis of the nptII Gene in the Transformants}

Quantitative real-time PCR was performed to quantify the efficiency of genomic integration and transcription of the introduced nptII genes in T. minus transformants. Figure 6 shows their quantitative results in the cDNA obtained from three independent transgenic cells of T. minus bombarded with pEASY-tub-nptII under 450 and 900 psi, respectively. The endogenous tub gene was utilized as a reference gene, and the samples from wild-type T. minus were used as the control. Normalized fold changes of the nptII gene in these transformants to the wild-type cells were calculated with the $t u b$ gene as a balance based on the $\Delta \Delta \mathrm{Ct}$ method. The signals of $n p t I I$ genes identified in the transformant genomes were calculated to be 235-394 times higher than those in the wild-type cDNA. All these results confirm that the plasmids were successfully integrated into the genome and expressed efficiently in T. minus transformants.

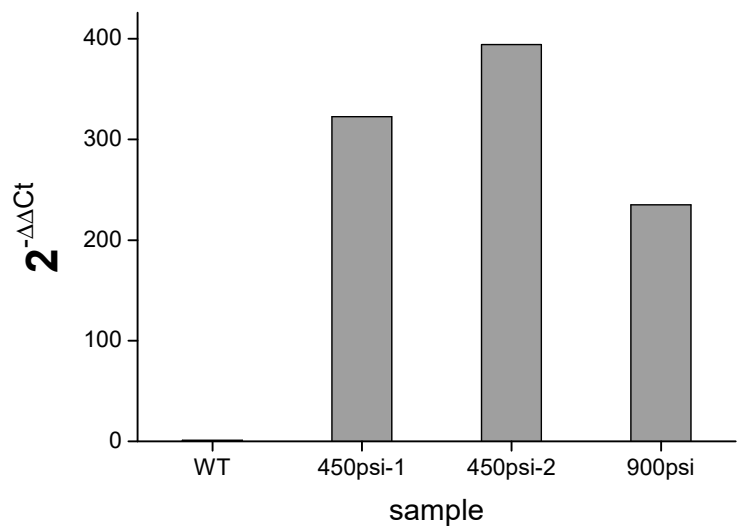

Figure 6. Quantification of the nptII gene in three transformants of T. minus through real-time PCR.

\section{Discussion}

Tribonema minus, which is classified within the family Xanthophyceae, has recently become an attractive organism for use in biotechnology. This alga has the ability to grow under autotrophic, 
mixotrophic, and heterotrophic conditions, and it can synthesize and accumulate a significant amount of fatty acid intracellularly [27]. Establishing genetic tools for T. minus would increase the potential value of this alga in biotechnological applications, and it could serve as a molecular model for Xanthophyceae.

Transformability is usually tested using a selection marker; thus, in order to develop a system for the efficient selection of transformants, knowledge about the sensitivity of a strain to various antibiotics is essential. Selectable marker genes, including neomycin phosphotransferaseII (nptII) [24], phleomycin-resistance (shble) [25], and streptothricin acetyltransferase (sat) [21], have been used for microalgae transformation. According to an antibiotics sensitivity trial, T. minus is very sensitive to G418 (neomycin); therefore, the resistance gene nptII was used in this study as the selection maker. Active promoters and terminators are important constitutions of efficient transformation and expression vectors. Researchers once chose heterologous eukaryotic vectors, such as SV 40 [28] or CaMV $35 S$ promoters [29], to drive foreign genes into microalgae cells; however, results showing successful transformation could not be repeated widely [30]. Generally, the utilization of endogenous vectors could greatly facilitate the integration and expression of foreign genes in the host genome [23]. Alpha tubulin $(t u b)$ is a principal component of microtubules that forms part of the cytoskeleton in eukaryotic cells [31], and its promoter and terminator have been widely utilized for the construction of efficient screening markers in different organisms [25]. Transcriptomic data show that the tub gene has a constitutive and high level of expression in T. minus. Thus, the upstream and downstream regions of endogenous tub could be considered to provide active promoter and terminator functions. In this work, the complete sequence of the $t u b$ gene, including its exons, introns, and $5^{\prime}$ and $3^{\prime}$ flanking sequences were successfully identified in T. minus. Subsequently, a fusion PCR method was performed to fuse the genes of $e$ GFP and nptII with the tub promoter (1373 bp) and terminator (574bp) of T. minus, respectively. Finally, two vectors that were controlled by the endogenous tub promoter and terminator with sizes of 6124 and $6580 \mathrm{bp}$ were successfully constructed and named pSimple-tub-eGFP and pEASY-tub-nptII, respectively.

During biolistic transformation manipulation, many manipulation details influenced the success rate [32]. The culture phase and growth status of microalgae cells are very important for bombardments. When a late-stage culture with predominantly $H$. pluvialis cells was used for bombardment, no successful transformation was achieved. However, the transient expression of a gene could be served in a logarithmic culture with cells after bombardment $[25,28]$. In this work, we also chose the cells at the logarithmic phase and gave a short incubation period for cells on a solid medium plate. Moreover, the transformation of microalgae cells could also be influenced by the pressure of bombardment. In our former tests, T. minus cells were easily shattered as the tungsten powder appeared on the filter membrane under higher pressure conditions. Hence, we layered a piece of filter membrane on the upper part of the cells prepared for transformation under a pressure of $900 \mathrm{psi}$ and higher. Transformation was achieved successfully under only two lower pressure conditions of 450 and 900 psi. The effective pressures were lower than those used in the genetic transformation of a unicellular green microalgae Pseudochoricystis ellipsoidea, the bombardment of which can achieve success from 900 to 1550 psi [33]. This might be related to the loose degree of filaments and gives fundamental manipulation parameters for the bombardment of filamentous microalgae.

Different from unicellular microalgae, the transformant screening of filamentous T. minus was carried out on agar plates of G418-containing medium followed by further resistant treatment in liquid medium. For unicellular microalgae, the transformant colonies could be easily observed on the agar plates [34,35]; however, it was difficult to grow a colony of T. minus transformants instead of a flake or a speck of green cells on the agar plates (Figure $3 \mathrm{~A}$ ). a possible explanation is that although some single cells composed the filaments, they were not transformed into exogenous DNA, it was possible that they did not contact antibiotics directly due to their filamentous characteristics. However, the single transformant cells could give many new transgene cells due to the genus growing by cell division [26], but those cells in the same filament that did not transform successfully would die under long-term antibiotic treatment. Therefore, after agar-plate screening, we picked as few survival cells as possible 
and transferred them into liquid medium with a higher G418 concentration. After a period of resistant treatment, some cells showed a good growth status in liquid medium, while some died. The nptII fragment was amplified in the cells that grew well in antibiotic-containing liquid medium, which proved the success of transformation and resistant screening. Moreover, the results of the RT-PCR analysis confirmed that the plasmid was successfully integrated into the genome and expressed efficiently in T. minus transformants. Furthermore, to detect the stability of transformation, we subcultured the transformant and examined the partial vector fragment with a size of $803 \mathrm{bp}$, including part of the $n p t I I$ gene and part of the tub promoter at random. The final result clearly indicated that nptII was still in the transformant cells, at least in the third generation.

In conclusion, stable nuclear transformation was achieved for the first time in T. minus through biolistic bombardment using the nptII gene driven by transcriptional elements flanking the endogenous $t u b$ gene. This approach enriched the molecular tools for the genetic modification of T. minus, and a transformant screening flow was well established. On the basis of this, further research into the metabolic engineering and synthetic biology of T. minus should be done.

\section{Materials and Methods}

\subsection{Strain and Growth Conditions}

The yellow-green microalgae Tribonema minus SAG 880-3 was obtained from the Culture Collection of Algae of Gottingen University and maintained in our laboratory. T. minus cells were grown at $23 \pm 1{ }^{\circ} \mathrm{C}$ under continuous fluorescent light $\left(100 \mu \mathrm{mol} \mathrm{m} \mathrm{m}^{-2} \mathrm{~s}^{-1}\right)$ in liquid BG11 medium [36] that was continuously bubbled with air containing $1 \%(\mathrm{v} / \mathrm{v}) \mathrm{CO}_{2}$. The Escherichia coli strain DH5 $\alpha$ was used for the construction, propagation, and maintenance of plasmid. It was cultured in Luria-Bertani (LB) medium at $37^{\circ} \mathrm{C}$.

\subsection{Sensitivity to Herbicide and Antibiotics}

The effects of the herbicide basta (Sigma) and the antibiotics hygromycin, chloramphenicol, geneticin (G418), kanamycin, and streptomycin (Sigma) on T. minus in liquid BG11 medium were monitored. Aliquots of BG11 medium supplemented with varying concentrations of basta or each antibiotic $\left(10,20,50,70,100\right.$, or $\left.150 \mu \mathrm{g} \mathrm{mL}^{-1}\right)$ were inoculated with freshly grown $T$. minus to an initial biomass concentration of $0.2 \mathrm{~g} \mathrm{~L}^{-1}\left(\mathrm{OD}_{680}\right.$ and density may not be accurate because of the filaments).

To further determine the sensitivity of T. minus to G418 on solid BG11 medium, aliquots of $200 \mu \mathrm{L}$ suspension $\left(0.2 \mathrm{~g} \mathrm{~L}^{-1}\right)$ were inoculated on agar plates containing different concentrations of G418 $(5,10$, 15 , and $\left.20 \mu \mathrm{g} \mathrm{mL}^{-1}\right)$. The flasks and agar plates were incubated under continuous light at an irradiance level of $60 \mu \mathrm{mol} \mathrm{m}^{-2} \mathrm{~s}^{-1}$ and $23 \pm 1^{\circ} \mathrm{C}$, and the growth of T. minus in the liquid and the solid medium was monitored at daily intervals for 10 days and 2 weeks, respectively. The sensitivity of T. minus to the antibiotics and the herbicide was repeated at least three times.

\subsection{Endogenous Promoter and Terminator Clone}

A homology search using BLASTX was performed with reference to the 13,751 genes from the transcriptomic sequence of T. minus to obtain tub genes. Through PCR with designed primers (Table 1), the tubulin $(t u b)$ gene was obtained and the nucleotide sequences comprised a promoter region and a terminator region from a tub gene in T. minus. Genome walking [37] with a Genome Walking Kit (TaKaRa Bio Inc., Kusatsu, Japan) was used to obtain the 3' flanking sequences of the $t u b$ gene. Three specific synthetic primers, tub-sp1, tub-sp2, and tub-sp3 (Table 1), were designed. Each primer had a relatively high annealing temperature. Three rounds of PCR were performed for each walking process using the product of the previous PCR as a template for the next PCR. Each PCR mixture had 1×LA PCR Buffer II (Mg2+ plus) containing 0.4 mM dNTP mixture, 2.55U TaKaRa LA Taq, $0.2 \mu \mathrm{M}$ of each primer, and a certain amount of template. The first round of PCR had three annealing stages: stage 1 had five high-stringency $\left(65^{\circ} \mathrm{C}\right)$ cycles; stage 2 had one low-stringency $\left(25^{\circ} \mathrm{C}\right)$ cycle; and stage 
3 had thirty high-stringency $\left(65^{\circ} \mathrm{C}\right)$ cycles. The next two rounds of PCR had two annealing stages: stage 1 had 30 high-stringency $\left(65^{\circ} \mathrm{C}\right)$ cycles and stage 2 had 15 low-stringency $\left(44^{\circ} \mathrm{C}\right)$ cycles. After agarose gel electrophoresis and gel extraction, the fragments were cloned into pEASY-T1 vectors and sequenced.

Table 1. Primers prepared for the $t u b$ promoter and terminator via genome walking.

\begin{tabular}{cc}
\hline Primers & Sequence $\mathbf{( 5}^{\prime} \mathbf{s}^{\prime} \mathbf{}^{\mathbf{}}$ \\
\hline tub-F & ATGCGTGAATGCATCAGCATCC \\
tub-R & CGGCACACGTCGTACAGGGCC \\
Ptub-sp1 & AGTAGAGCTCCCAGCAGGCATT \\
Ptub-sp3 & TTTCAGGGCATCGCTGCTTCAGTA \\
Ttub-sp1 & AGCGGAACTCATGCCGATCAGGTA \\
Ttub-sp2 & TAACCCCACTCCTCCTCGTCGCTTT \\
Ttub-sp3 & ATCAACTACCAGCCTCCCACCGT \\
\hline
\end{tabular}

\subsection{Construction of Plasmids for Transformation}

For the transformation, we constructed two vectors, the pSimple-tub-eGFP and pEASY-tub-nptII plasmids, in which the green fluorescent protein (eGFP) gene [38] and the neomycin phosphotransferase II-encoding G418-resistant gene (nptII) were flanked by the T. minus-derived tub promoter (Ptub) and terminator (Ttub), respectively. The a fusion PCR method was performed to fuse the nptII and eGFP genes with the $t u b$ promoter and terminator of T. minus, as described in a previous study [25]. Taking the construction of the tub/nptII cassette as an example, three target fragments, Ptub, nptII, and Ttub, were obtained by regular PCR with the primer pairs of Ptub-F/Ptub(nptII)-R, nptII-F/ $n p t I I-\mathrm{R}$, and Ttub(nptII)-F/Ttub-R, respectively (Table 2). The primers for pSimple-tub-eGFP are listed in Table 3. The three purified DNA fragments in equal mol amounts were mixed with $p f u$ DNA polymerase in a $50 \mu \mathrm{L}$ PCR reaction system. This mixture underwent a PCR fusion procedure as follows: a $10 \mathrm{~min}$ initial denaturation step at $95^{\circ} \mathrm{C}$ followed by thirteen cycles of denaturation for $30 \mathrm{~s}$ at $95{ }^{\circ} \mathrm{C}$, annealing for $30 \mathrm{~s}$ at $55^{\circ} \mathrm{C}$, extension for $2-3 \mathrm{~min}$ at $72{ }^{\circ} \mathrm{C}$, and a final $10 \mathrm{~min}$ extension step at $72{ }^{\circ} \mathrm{C}$. The final mixture was utilized as the template for PCR amplification of the target tub/nptII fragment with the primer pair of tub-f0/tub-r0. The resulting fusion fragments were cloned into the plasmid pEASY-T1. The verified plasmids were named pEASY-tub- nptII.

Table 2. Primers prepared for construction of pEASY-tub- nptII via fusion PCR.

\begin{tabular}{cc}
\hline Primers & Sequence $\left(\mathbf{5}^{\prime} \mathbf{3}^{\prime} \mathbf{}^{\prime}\right.$ \\
\hline Ptub-F & CAGTGCAGTCATCTGCTGCGGGC \\
Ptub $(n p t I I)-\mathrm{R}$ & GCAATCCATCTTGTTCAATCATGTTGACTGGAGAAGTGGTCCTGC \\
$n p t I I-\mathrm{F}$ & GCAGGACCACTTCTCCAGTCAACATGATTGAACAAGATGGATTGC \\
$n p t I I-\mathrm{R}$ & GTGCACACGTCAACAGTGCGCTCAGAAGAACTCGTCAAGAAGG \\
Ttub $(n p t I I)-\mathrm{F}$ & CCTTCTTGACGAGTTCTTCTGAGCGCATGTTGACGTGTGCAC \\
Ttub-R & GGGCGATTGGGCCCTGTAGATGC \\
\hline
\end{tabular}

Table 3. Primers prepared for the construction of pSimple-tub-eGFP via fusion PCR.

\begin{tabular}{cc}
\hline Primers & Sequence $\mathbf{( 5}^{\prime}-\mathbf{3}^{\prime}$ ) \\
\hline Ptub-F & GAATTCTCATGGCGCGACGCTGT \\
Ptub(eGFP)-R & eGFP-F \\
eGF- $\mathrm{R}$ & GCTCCTCGCCCTTGCTCACCATGGTGGCCTTTAAGGGTGCTGTTTAAACTGC \\
Ttub(eGFP)-F & GCAGTTTAAACAGCACCCTTAAAGGCCACCATGGTGAGCAAGGGCGAGGAGC \\
Ttub-R & GTGGGCCTGAGCGTCATGTTACTTGTACAGCTCGTCCATG \\
CATGGACGAGCTGTACAAGTAAACATGACGCTCAGGCCCAC \\
GGTTCATCTGCTGACGAGTGCT \\
\hline
\end{tabular}

\subsection{Particle Bombardment}

For transformation, T. minus cultures at the logarithmic growth phase were pelleted by filtration and suspended in BG11 medium to a biomass concentration of 2-3 $\mathrm{g} \mathrm{L}^{-1}$. Then, a $2 \mathrm{~mL}$ aliquot of cell 
suspension was layered directly onto the central area of an MF-Millipore membrane filter (Millipore, Bedford, MA, USA), which was placed on a BG11 solid plate. After growth for 2 days, the samples were used as the recipient cells for transformation.

The bombardment was performed with a PDS-1000/He Biolistic Particle Delivery system (Bio-Rad, USA). Plates were bombarded from a distance of $6 \mathrm{~cm}$ and bombarded under vacuum pressure at $125 \mathrm{~mm} \mathrm{Hg}$ using helium pressures of 450, 900, 1100, and 1350 psi to accelerate particles. DNA coated particles were prepared by mixing $50 \mu \mathrm{L}$ of 17 tungsten particle solution $\left(60 \mathrm{mg} \mathrm{mL}^{-1}\right.$ in $\left.\mathrm{H}_{2} \mathrm{O}\right)$ with $5 \mu \mathrm{L}$ of a DNA solution $\left(>1 \mu \mathrm{g} \mu \mathrm{L}^{-1}\right), 50 \mu \mathrm{L}$ of $2.5 \mathrm{M} \mathrm{CaCl}_{2}$, and $20 \mu \mathrm{L}$ of $0.1 \mathrm{M}$ spermidine base. This was followed by 10 min incubation on ice and two centrifugal washes with $70 \%$ and then $100 \%$ ethanol before final resuspension in about $50 \mu \mathrm{l}$ ethanol. a total of $10 \mu \mathrm{L}$ of prepared DNA-coated particle solution was layered on a microcarrier for one trial.

After transformation, cells on the membrane were transferred into $10 \mathrm{~mL}$ of fresh BG11 medium and incubated at $23 \pm 1{ }^{\circ} \mathrm{C}$ under dark conditions for 2 days for regeneration. Then, $200 \mu \mathrm{L}$ of culture transformed with pEASY-tub-nptII were plated onto BG11 agar plates containing $10 \mu \mathrm{g} \mathrm{mL}^{-1} \mathrm{G} 418$. After 2-3 weeks, the cells grown on the plates were picked up and resuspended in $20 \mathrm{~mL}$ of BG11 medium supplemented with $20 \mu \mathrm{g} \mathrm{mL}^{-1} \mathrm{G} 418$ and incubated under continuous fluorescent light with $60 \mu \mathrm{mol}$ photons $\mathrm{m}^{-1} \mathrm{~s}^{-1}$ at $23 \pm 1{ }^{\circ} \mathrm{C}$ for further transgenic cell screening.

\subsection{Fluorescence Detection of eGFP Gene Expression}

pSimple-tub-eGFP transformants grown in medium were used for the fluorescence analysis along with wild-type T. minus cells as a negative control. Leica DM14000 (Leica Microsystems, Germany) was used to examine eGFP expression using excitation at $488 \mathrm{~nm}$. Detection was in the range of $495-556 \mathrm{~nm}$ for $e G F P$ and $685-735 \mathrm{~nm}$ for chloroplast autofluorescence.

\subsection{Preparation of Genomic DNA and PCR Analysis}

The G418-resistant T. minus cells were disrupted by grinding in liquid nitrogen with a mortar and pestle and transferred to a $1.5 \mathrm{~mL}$ microcentrifuge tube. The cells were suspended in TEN buffer $(10 \mathrm{mM}$ Tris- $\mathrm{HCl}, \mathrm{pH}$ 8.0, $150 \mathrm{mM} \mathrm{NaCl}, 10 \mathrm{mM}$ EDTA). After phenol/chloroform/isoamylalcohol extraction and 2-propanol precipitation, samples were treated with RNase A, and the genomic DNA was recovered by ethanol precipitation following phenol/chloroform/isoamyl alcohol and chloroform treatments.

Genomic PCR was performed with isolated $0.1 \mu \mathrm{g}$ genomic DNA as a template and $5 \mu \mathrm{L}$ of Go Taq Master Mix. Amplifications were performed by incubating reaction mixtures at $95^{\circ} \mathrm{C}$ followed by $20 \mathrm{~s}$ at $52.5^{\circ} \mathrm{C}$ and $60 \mathrm{~s}$ at $72{ }^{\circ} \mathrm{C}$. Assays with no template were examined for every experiment as a negative control.

\subsection{Continuous Cultivation of Transformants}

The G418-resistant T. minus transformants were harvested via filtration. After being washed with distilled water twice, the cells were transferred into fresh BG11 medium for subculture. The extracted genomic DNA and PCR analysis of the resistant gene from transformants, which was cultured to the third generation, were examined and analyzed as described above.

\subsection{Quantitative Real-Time PCR Analysis}

Total RNA was prepared by the ConcertTM Plant RNA Reagent (Invitrogen, Carlsbad, CA, USA) according to the manufacturer's instructions and purified with an RNeasy Mini Kit column (QIAGEN, Hilden, Germany). The purified RNA $(1.5 \mu \mathrm{g})$ was transcribed into cDNA by employing the Transcriptor High Fidelity cDNA Synthesis Kit (Roche Applied Science, Mannheim, Germany), as described by the manufacturer. PCR was performed as for the genomic PCR analysis described above with slight modifications. The conditions of the PCR were as follows: $95^{\circ} \mathrm{C}$ for 2 min prior to 25 cycles of $15 \mathrm{~s}$ at $95^{\circ} \mathrm{C}$, followed by $20 \mathrm{~s}$ at $52.5^{\circ} \mathrm{C}$ and $60 \mathrm{~s}$ at $72{ }^{\circ} \mathrm{C}$. Assays with samples that were 
prepared without reverse transcriptase in the cDNA synthesis reaction and with no template were examined for every experiment as a negative control.

Author Contributions: Y.Z. carried out the experiments and performed the data processing, H.W. was involved in the conceptual design and drafted the manuscript, G.Y. gave some suggestions on the conceptual design, R.Y. and L.W. helped with the experiment manipulation, and T.L. helped to draft and revise the manuscript. All authors have read and agreed to the published version of the manuscript.

Funding: This work was financially supported by the National Natural Science Foundation of China (Grant No. 31702313), the Strategic Priority Research Program of the Chinese Academy of Sciences (Transformational Technologies for Clean Energy and Demonstration, XDA21010211), DICP\&QIBEBT UN201801 (Grant: DICP\&QIBEBT UN201801), and the Dalian National Laboratory for Clean Energy (DNL), CAS.

Conflicts of Interest: The authors declare no conflict of interest.

\section{References}

1. Hu, Q.; Sommerfeld, M.; Jarvis, E.; Ghirardi, M.; Posewitz, M.; Seibert, M.; Darzins, A. Microalgal triacylglcerols as feedstocks for biofuel production: Perspectives and advances. Plant J. 2008, 54, 621-639. [CrossRef]

2. Irina, A.G.; John, L.H. Lipids and lipid metabolism in eukaryotic algae. Prog. Lipid Res. 2006, 45, 160-186.

3. Liang, J.B.; Wen, F.; Liu, J.H. Transcriptomic and lipidomic analysis of an EPA-containing Nannochloropsis sp. PJ 12 in response to nitrogen deprivation. Sci. Rep. 2019, 9, 4540. [CrossRef]

4. William, P.L.I.B.; Laurens, L.M.L. Microalgae as biodiesel and biomass feedstocks: Review and analysis of the biochemistry, energetics and economics. Energy Environ. Sci. 2010, 3, 554-590. [CrossRef]

5. Adrme-Vega, T.C.; Lim, D.K.; Timmins, M.; Vernen, F.; Li, Y.; Schenk, P.M. Microalgal biofactories: a proming approach towards sustainable omega-3 fatty acid production. Microb. Cell Facotries 2012, 11, 96. [CrossRef]

6. Wang, H.; Gao, L.L.; Chen, L.; Guo, F.J; Liu, T.Z. Integration process of biodiesel production from filamentous oleaginous microalgae Tribonema minus. Bioresour. Technol. 2013, 142, 39-44. [CrossRef] [PubMed]

7. Wang, H.; Zhou, W.J.; Shao, H.M.; Liu, T.Z. a comparative analysis of biomass and lipid content in five Tribonema sp. strains at autotrophic, heterotrophic and mixotrophic cultivation. Algal Res. 2017, 24, 284-289. [CrossRef]

8. Zhou, W.J.; Wang, H.; Chen, L.; Cheng, W.T.; Liu, T.Z. Heterotrophy of filamentous oleaginous microalgae Tribonema minus for potential production of lipid and palmitoleic acid. Bioresour. Technol. 2017, 239, 250-257. [CrossRef] [PubMed]

9. Wang, H.; Zhang, Y.; Zhou, W.J.; Noppol, L.; Liu, T.Z. Mechanism and enhancement of lipid accumulation in filamentous oleaginous microalgae Tribonema minus under heterotrophic condition. Biotechnol. Biofuels 2018, 11, 328. [CrossRef] [PubMed]

10. Couso, A.; Vila, M.; Rodriguez, H.; Vargas, M.A.; Leon, R. Overexpression of an exogenous phytoene synthase gene in the unicellular alga Chlamydomonas reinhardtii leads to an increase in the content of carotenoids. Biotechnol. Prog. 2011, 27, 54-60. [CrossRef] [PubMed]

11. Mussgnug, J.H. Genetic tools and techniques for Chlamydomonas reinhardtii. Appl. Microbiol. Biotechnol. 2015, 99, 5407-5418. [CrossRef] [PubMed]

12. Ajjwai, I; Verruto, J.; Aqui, M.; Soriage, L.B.; Coppersmith, J.; Kwok, K. Lipid production in Nannochloropsis gaditana is doubled by decreasing expression of a single transcriptional regulator. Nat. Biotechnol. 2017, 35, 647-652. [CrossRef] [PubMed]

13. Vieler, A.; Wu, G.X.; Tsai, C.H. Genome, functional gene annotation, and nuclear transformation of the heterokont oleaginous alga Nannochloropsis oceanica CCMP1779. PLoS Genet. 2012, 8, e1003064. [CrossRef] [PubMed]

14. Kumar, M.; Jeon, J.; Choi, J.; Kim, S.R. Rapid and efficient genetic transformation of the green microalga Chlorella vulgaris. J. Appl. Phycol. 2018, 30, 1735-1745. [CrossRef]

15. Radakovits, R.; Eduafo, P.M.; Posewitz, M.C. Genetic engineering of fatty acid chain length in Phaeodactylum tricornutum. Metab. Eng. 2011, 13, 89-95. [CrossRef]

16. Perin, G.; Bellan, A.; Segalla, A.; Meneghesso, A.; Alboresi, A.; Morosinotto, T. Generation of random mutants to improve light-use efficiency of Nannochloropsis gaditata cultures for biofuels production. Biotechnol. Biofuels 2015, 8, 161. [CrossRef] 
17. Wei, L.; Xin, Y.; Wang, Q.T.; Yang, J.H.; Hu, H.; Xu, J. RNAi-based targeted gene knockdown in the model oleaginous microalgae Nannochloropsis oceanica. Plant J. 2017, 89, 1236-1250. [CrossRef]

18. Berrios, H.; Zapata, M.; Rivas, M. a method for genetic transformation of Botryococcus braunii using a cellulase pretreatment. J. Appl. Phycol. 2016, 28, 201-208. [CrossRef]

19. Liu, L.; Wang, Y.; Zhang, Y.; Chen, X.; Zhang, P.; Ma, S. Development of a new method for genetic transformation of the green alga Chlorella ellipsoidea. Mol. Biotechnol. 2013, 54, 211-219. [CrossRef]

20. Hamilton, M.L.; Haslam, R.P.; Napier, J.A.; Sayanova, O. Metabolic engineering of Phaeodactylum ricornutum for the enhanced accumulation of omega-3 long chain polyunsaturated fatty acids. MET Eng. 2014, 22, 3-9. [CrossRef]

21. Zaslavskaia, L.A.; Lippmeier, J.C.; Kroth, P.G.; Grossman, A.R.; Apt, K.E. Transformation of the diatom Phaeodactylum tricornutum (Bacillaripphyceae) with a variety of selectable marker and reporter genes. J. Phycol. 2000, 36, 379-386. [CrossRef]

22. Anami, S.; Njuguna, E.; Coussens, G.; Aesaert, S.; van Lijsebettens, M. Higher plant transformation: Principles and molecular tools. Int. J. Dev. Biol. 2013, 57, 483-494. [CrossRef] [PubMed]

23. Radakovits, R.; Jinkerson, R.; Darzins, A.; Posewitz, M. Genetic engineering of algae for enhanced biofule prodution. Eukayot. Cell 2010, 9, 486. [CrossRef] [PubMed]

24. Judith, N.; Alic, M.; Lenka, B.; Jason, D.; Atle, M.B.; Roman, S. Tools for biotechnological studies of the freshwater alga Nannochloropsis limnetica: Antibiotic resistance and protoplast production. J. Appl. Phycol. 2017, 29, 853-863.

25. Yuan, G.H.; Xu, X.Y.; Zhang, W.; Zhang, W.L.; Cui, Y.L.; Qin, S.; Liu, T.Z. Biolistic transformation of Haemotococcus pluvialis with constructs based on the flanking sequences of its endogenous alpha tubulin gene. Front. Microbiol. 2019, 10, 1749. [CrossRef]

26. Ivan, K.K.; Katya, N.V.; Krasimira, D.D. Species composition and distribution of genus Tribonema (Xanthophyceae) in Bulgaria. Phytol. Balc. 2011, 17, 273-277.

27. Zhou, W.J.; Wang, H.; Zheng, L.; Cheng, W.T.; Gao, L.L.; Liu, T.Z. Comparison of lipid and palmitoleic acid induction of Tribonema minus under heterotrophic and phototrophic regimes by using high-density fermented seeds. Int. J. Mol. Sci. 2019, 20, 4356. [CrossRef]

28. Teng, C.Y.; Qin, S.; Liu, J.; Yu, D.Z.; Liang, C.W.; Tseng, C.K. Transient expression of lacZ in bombarded unicellular green alga Haematococcis pluvialis. J. Appl. Phycol. 2002, 14, 497-500. [CrossRef]

29. Kathiresan, S.; Sarada, R. Towards genetic improvement of commercially imporant microalga Haematococcus pluvialis for biotech applications. J. Appl. Phycol. 2009, 21, 553-558. [CrossRef]

30. Sharon-Gojman, R.; Maimon, E.; Leu, S.; Zarka, A.; Boussiba, S. Advanced methods for genetic engineering of Haeatococcus pluvialis (Chlorophyceae, Volvocales). Algal Res. 2015, 10, 8-15. [CrossRef]

31. Bandziulis, R.J.; Rosenbaum, J.L. Novel control elements in the alpha-1 tubulin gene promoter from Chlamydomonas reinhardii. Mol. Gen. Genet. 1988, 214, 204-212. [CrossRef] [PubMed]

32. Elghavi, Z.; Ruf, S.; Bock, R. Biolistic co-transformation of the nuclear and plastid genomes. Plant J. 2011, 67, $941-948$. [CrossRef] [PubMed]

33. Iammura, S.; Hagiwara, D.; Suzuki, F.; Kurano, N.; Harayama, S. Genetic transformation of Pseudochoricystis ellipsoidea, an aliphatic hydrocarbon-producing green alga. J. Gen. Appl. Microbiol. 2012, 58, 1-10. [CrossRef] [PubMed]

34. Guo, S.L.; Zhao, X.Q.; Tang, Y.; Wan, C.; Alam, M.A.; Ho, S.H.; Bai, F.W.; Chang, J.S. Establishment of an efficient genetic transformation system in Scenedesmus obliquus. J. Biotechnol. 2013, 163, 61-68. [CrossRef] [PubMed]

35. Zorin, B.; Grundman, O.; Khozin-Goldberg, I.; Leu, S.; Shapira, M.; Kaye, Y.; Tourasse, N.; Vallon, O.; Boussiba, S. Development of a nuclear transformation system for oleaginous green alga Lobosphaera (Prietochloris) incisa and genetic complementation of a mutant strains, deficient in arachldonic acid biosynthesis. PLoS ONE 2014, 9, e105223. [CrossRef]

36. Boussiba, S.; Vonshak, A. Astaxanthin accumulation in the green alga Haematocottus pluvialis. Plant Cell Physiol. 1991, 32, 1077-1082. [CrossRef] 
37. Li, H.X.; Ding, D.Q.; Cao, Y.S.; Yu, B.; Guo, L.; Liu, X.H. Partially overlapping primer-based PCR for genome walking. PLoS ONE 2015, 10, e0120139. [CrossRef]

38. Siemering, K.R.; Golbik, R.; Sever, R.; Haseloff, J. Mutations that suppress the thermosensitivity of green fluorescent protein. Curr. Biol. 1996, 6, 1653-1663. [CrossRef]

(C) 2020 by the authors. Licensee MDPI, Basel, Switzerland. This article is an open access article distributed under the terms and conditions of the Creative Commons Attribution (CC BY) license (http://creativecommons.org/licenses/by/4.0/). 